\title{
Ecophysiological Studies of A Cereal Crop Oryza sativa L. with Zinc Stress
}

\author{
Sasmita Kumari Behura*, Mamata Mohapatra, B.K. Mohanty \\ P.G. Department of Botany and Biotechnology, Khallikote Autonomous College, Berhampur - 760 001, Odisha, India.
}

\section{ARTICLEDETAILS}

\section{Article history:}

Received 14 October 2018

Accepted 06 November 2018

Available online 06 December 2018

\section{Keywords:}

Cereal

Zinc

Oryza

\begin{abstract}
A B S T RAC T
Plants exposed to zinc stress at high concentration inhibit seed germination, seedling growth and development. The germination data showed that there is a negative impact of concentration of zinc sulphate on the germination of seeds. Root and shoot growth of seedlings was worse affected when exposed to higher concentration on $\mathrm{ZnSO}_{4}$. Shoots were more affected than roots. Morphologically they look different from normal roots by their shape and size. Zn toxicity inhibits the chlorophyll formation and with the increase in concentration of the toxicant the exposed seedlings showed a decline in chl- $a$ (chlorophyll-a), chl- $b$ (chlorophyll - b) and total chlorophyll pigment content. Conclusively, our result shows that zinc sulphate at higher concentration decreases seed germination, chl- $a$, chl- $b$ and total chlorophyll content and also decreases root and shoot growth of plants.
\end{abstract}

\section{Introduction}

Pesticides treated to seeds have tendency to penetrate into tissue of the plants. There, they transformed into metabolites, which are physiologically more active than the parent compounds and finally affects the seed health and quality. Herbicides treatment was found to be inhibiting the uptake of potassium ions and rice seedling growth. In order to accumulate $\mathrm{Zn}$ in grains, rice plants have to uptake, mobilize, and transport Zn from soil to grain, which involves many complex physiological processes at different levels within the rice plant, provided there is an adequate supply of $\mathrm{Zn}$ in the soil. In general there are three major rate of limiting steps or barriers for efficient $\mathrm{Zn}$ accumulation in rice grain: 1) soil-to-root barriers; 2) root-to-shoot barriers; and (3) barriers in loading $\mathrm{Zn}$ into grains. Root uptake is the first step towards the accumulation of $\mathrm{Zn}$ in rice grains.

The availability of soil $\mathrm{Zn}$ for rice from flooded (anaerobic) soil is affected by an additional set of factors such as soil redox potential, total sulfur content, and soluble bicarbonate. Thus, a combination of agronomic management practices and genetic approaches are essential to improve the soil health conditions to enhance the root uptake of $\mathrm{Zn}$. In rice, direct root uptake, remobilizations from vegetative tissues or combination of both of these two approaches are the main source of $\mathrm{Zn}$ in grains [1]. There is a continuous xylem flow from root to grain mediated by transpiration system, which can directly transport $\mathrm{Zn}$ to grains [2]. However $\mathrm{Zn}$ movement is restricted by the presence of barriers for root-to-shoot transfer and for internal allocation and reallocation of $\mathrm{Zn}$ within and between vegetative and reproductive tissues, which leads to reduced accumulation of $\mathrm{Zn}$ in grains [3].

Plant factors that affect root $\mathrm{Zn}$ uptake include root architecture, root hairs, crown root development, root surface area, root anatomical structures and modification of rhizosphere chemistry through exudation of protons, which can change soil $\mathrm{pH}$, thereby improve the solubility of $\mathrm{Zn}$ in the soil and facilitate its diffusion to the root surface. Soil factors that affect the plant-availability of $\mathrm{Zn}$ for all crops includes soil $\mathrm{pH}$, texture, organic matter content, mineralogy, and microbial populations [4].

Even though there are huge amounts of $\mathrm{Zn}$ in vegetative tissues of rice plants, remobilization of $\mathrm{Zn}$ from vegetative tissues to reproductive tissues and finally to grains is limited due to selective phloem transport of Zn from old tissues to new tissues and to the grains $[1,5]$. Flag leaf, which plays an important role in photosynthesis and grain yield, were found to have a little contribution to grain $\mathrm{Zn} \mathrm{[6],} \mathrm{Wu}$, et al. reported significant translocation of $\mathrm{Zn}$ from flag leaf to the grain. A continuous supply of $\mathrm{Zn}$ to different tissues throughout the life cycle by translocation and phloem remobilization to grains is an important feature of $\mathrm{Zn}$ efficient rice genotypes [7]. It is also interesting to note that at lower tissue $\mathrm{Zn}$ concentrations, most of the $\mathrm{Zn}$ was found in leaf and reproductive tissues, while at higher $\mathrm{Zn}$ levels, stem and roots showed increased $\mathrm{Zn}$. Also, the increased root uptake of $\mathrm{Zn}$ and root to shoot transfer could not proportionately increase the grain $\mathrm{Zn}$ concentrations indicating that internal translocation/retranslocation of $\mathrm{Zn}$ from vegetative tissues to grains is the major bottleneck for improving grain $\mathrm{Zn}$ concentrations [7, 8].

Though, a number of physiological studies have been published about $\mathrm{Zn}$-efficient rice, little is known on how $\mathrm{Zn}$ is redistributed and remobilized from vegetative tissues to the grains [9].

A better understanding of the mechanisms involved in loading of $\mathrm{Zn}$ into the endosperm of rice and identification of rice genotypes with better $\mathrm{Zn}$ remobilization capacity without having any adverse effect on yield will be highly useful for $\mathrm{Zn}$ biofortification of rice $[5,10]$. Rice has also been found to show different levels and patterns of $\mathrm{Zn}$ accumulation under high or low $\mathrm{Zn}$ conditions and in different rice ecosystems [11-13].

\section{Experimental Methods}

\subsection{Selection of Rice Cultivars (Experimental Plant)}

Oryza sativa L. is a common cereal crop in Odisha and widely cultivated Oryza sativa L. Pooja is widely cultivated cereal crop by the local farmers in Odisha which are likely to expose heavy metal stress and there is a need to study the effects of different concentration of heavy metal. The poojadhan (IR74371-70-1-1) a drought tolerant variety developed at IRRI, New Delhi.

\subsection{Seed Selection}

Pure line of Oryza sativa L. Pooja is procured from OUAT Ratanpur, Berhampur, is used for experiment. These certified seeds are examined under preliminary selection for uniformity of size, shape and colour. The healthy and uniform seeds were sorted out by sieving and sorting before experiment.

\subsection{Test Chemical}

Zinc sulphate $\left(\mathrm{ZnSO}_{4}\right)$ was used as the test chemical. First stock solution of $1000 \mathrm{mg} / \mathrm{L}$ was prepared by dissolving $1 \mathrm{~g}$ of test chemical in $1 \mathrm{~L}$ of distilled water, different concentration of solution of $25,50,75,100 \mathrm{mg} / \mathrm{L}$ 
prepared by proportional dilution with distilled water which is used for various treatments.

\subsection{Study of Seed Viability}

The seeds were soaked with distilled water or different concentration of test solution from 12-14 h. After scheduled period of exposure, the seeds were washed with tap water, followed by distilled water and their viability was tested according and the result was expressed as \% of mortality of seed grains.

\subsection{Germination Studies}

The seeds of Oryza sativa L. Pooja showed 90\% germination during September-December. For germination studies sterilized plastic bowls were used for the study. Sterilized absorbent cotton clothes were spread on the bowls where test chemicals or distilled water were added to it Seeds were soaked for $24 \mathrm{hr}$ in the desired concentration of water, 15 numbers of seeds were sown in each bowl at uniform distance in all the sets. The cotton clothes and soil were made to wet at regular interval with distilled water and respective concentration of the test chemical $(25,50$, $75,100 \mathrm{mg} / \mathrm{L})$. The bowls were placed under mild sunlight. The emergence of radical or plumule was considered as an index of germination. Seeds were allowed to germinate. Better sprouted and healthy seedling of 10 days old were used as experimental material. Care was taken to avoid drying and over flooding of test chemical in the bowls.

\subsection{Selection of Effective Concentration}

Pilot experiment indicates that the metal exerts both promoting and retarding effect on the germination and seedling growth of the plant and it was essential to select a limited no. of concentration for further experiments. Thus four concentration of $\mathrm{ZnSO}_{4} 25,50,75,100 \mathrm{mg} / \mathrm{L}$ were selected. The data obtained from the germination and seedling growth experiments are used for screening.

\subsection{Morphological Studies}

The growth of plant was evaluated by measuring the shoot and root length of seedlings on $11^{\text {th }}$ day. $15 \mathrm{~cm}$ scale was used for the measurement of the shoot and root length.

\subsection{Biochemical Studies}

Biochemical studied were made using 10 day's old seedling. For this purpose seedlings were grown as described as before. However, in this case in addition to the control, 4 concentration $(\mathrm{mg} / \mathrm{L})$ of the metal $(25$, $50,75,100 \mathrm{mg} / \mathrm{L})$ selected by a preliminary screening were used for the growth of the plants. The root and shoot portion of the 10 days old seedling were separated, weighted and analyzed for various biochemical components.

\subsection{Estimation of Chlorophyll}

The fresh samples of shoot materials of the 10 days old seedlings were collected. Care was taken for separation of each control and treated samples. A known quality of about $100 \mathrm{mg}$ of samples of weighted shoot material was taken in a mortar and pestle and macerated the paste by adding $80 \%$ acetone was added, stirred thoroughly and again centrifuged (20 min.). Both supernatants were mixed together and the volume was made to $10 \mathrm{~mL}$. The residue was kept for protein estimation. The absorbance of each extract was determined in a spectrophotometer at a wavelength of 610 and $700 \mathrm{~nm}$ of wavelength.

The total chlorophyll (chl), chl- $a$, chl- $b$ content was measured by recording the absorbance of the extract at 610 and $700 \mathrm{~nm}$ wavelength and the values were calculated by using the formula given by Arnon (1949, 1959) [14].

\section{Results and Discussion}

The changes in root and shoot length of 10 days old seedling were shown in table and figure. The radical emerged with in $48 \mathrm{hrs}$. Incubation in the dark room at temperature. The emergence of radical or plumule was considered as index of germination. The seeds are exposed to light after germination. In the next day after exposing the seeds to light there was rapid elongation of radicle and plumule. At the end of $92 \mathrm{hrs}$, the most of seeds showed radicle emergence and there was rapid elongation of primary root and shoot splits from coleoptiles and emerged as primary leaf. At the end of $10^{\text {th }}$ day, the seedling showed primary root with adventitious roots (nodal roots), a number of rootlets and fully expanded $1^{\text {st }}$ and $2^{\text {nd }}$ leaf in control.

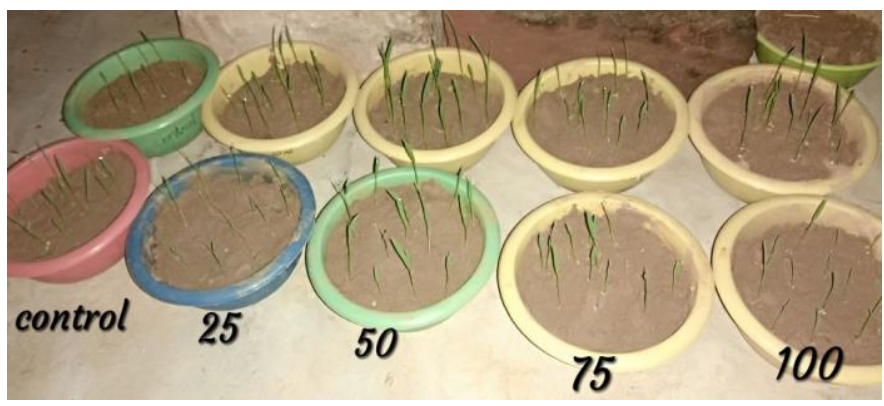

Fig. 1 Photo showing the growth of Rice seedlings (up to10 days) after zinc stress at varied concentrations of $\mathrm{ZnSO}_{4}$

The root length and shoot length were measured in the seedling after treatment with different concentration of zinc sulphate for 10 days (Figs. 1-5). From the table and figures, data clearly indicates a sharp decline in root and shoot of seedlings. As we increased the concentration of zinc sulphate the root and shoot length decreased. On the whole there was an inverse relationship between zinc concentration and seedling growth. The ratio of root to shoot length was also shown in table. The ratio also decreased constantly from control (1.73) to high concentration of $\mathrm{ZnSO}_{4}$ at $100 \mathrm{mg} / \mathrm{L}(1.95)$.

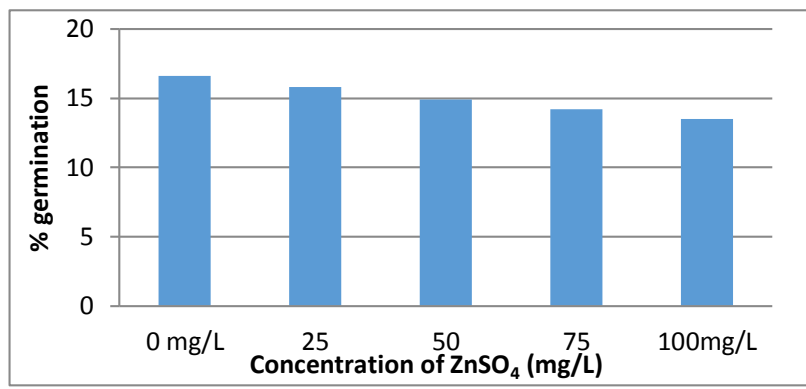

Fig. 2 Percentage germination of rice seeds in response to $\mathrm{Zn}$ stress

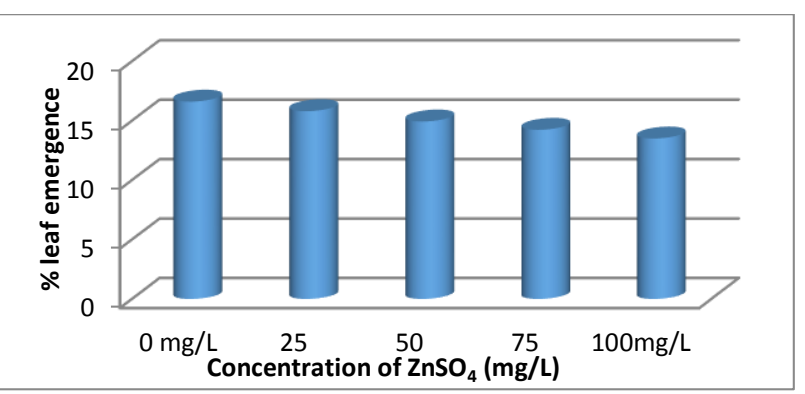

Fig. 3 Percentage of leaf emergence (168 h) in rice seedlings after Zn stress

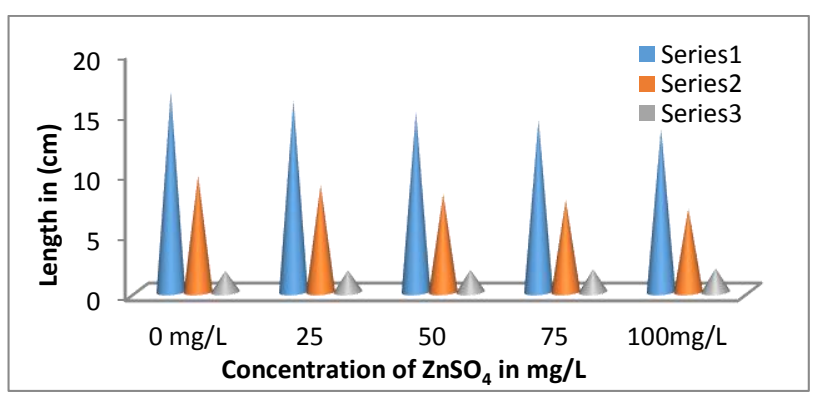

Fig. 4 Changes in root length (Series 1 ), shoot length (Series 2 ) and R/S ratio (Series 3) 10 days old in rice seedlings after Zn stress

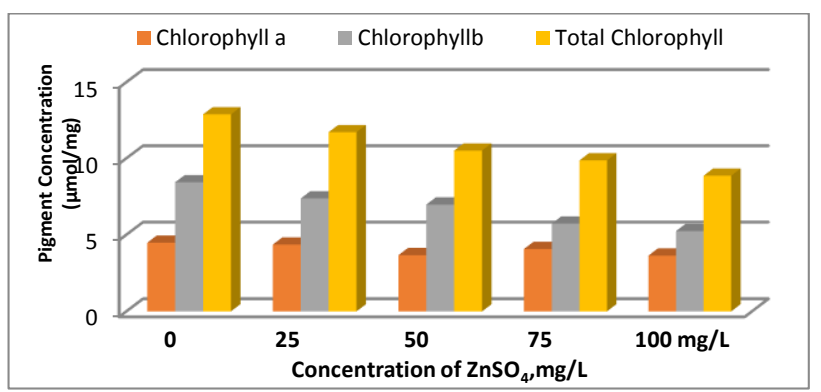

Fig. 5 Pigment concentration in rice seedlings (10 days old) after Znic stress 
There were visible changes seen in the roots which appeared different from that of the control. There was marked difference in the development of primary roots and adventitious roots. On exposure to high concentration beyond $50 \mathrm{mg} / \mathrm{L}$ there was a reduction in the primary roots, no lateral roots developed, and blackening or browning of root tip. Shoot elongation affected as we increased the concentration of test chemical. Chlorosis of leaves, patchy brown spots on leaves, necrotic lesions on leaves and eventually senescence of leaves starts at higher concentration.

Effect of the test chemical on the chlorophyll contents against the control and percentage in the pigment are presented. Slightly decreased in chlorophyll pigment were observed in increase in the concentration of $\mathrm{ZnSO}_{4}$. The percent change in the amount of chl- $a$, chl- $b$, and total chlorophyll of the exposed seedlings of $1000 \mathrm{mg} / \mathrm{l}$ was showed a fall.

$\mathrm{Zn}$ efficiency, which is used synonymously with $\mathrm{Zn}$ deficiency tolerance, reflects the ability of a plant to grow and yield well under Zn-deficient conditions. The proposed physiological mechanisms for Zn efficiency in rice at the early vegetative growth stage can be grouped into two categories: those related to increased root uptake of $\mathrm{Zn}$ and those related to internal $\mathrm{Zn}$ distribution. Mechanisms for increased root uptake in rice include proliferation of crown root growth, exudation of organic acids or phytosiderophores, and increased tolerance of radical oxygen stress.

The present study, exposure of $\mathrm{ZnSO}_{4}$ stress and its responses at different parameters of Pooja variety of rice seedling: germination studies, seedling growth, chl- $a$, chl- $b$, and total chlorophyll content.

In the present study on exposure of rice seedling to high concentration of $\mathrm{ZnSO}_{4}$ decreases the chl- $a$, chl- $b$, total chlorophyll. In general, decrease in germination has been one of the important manifestations of metal toxicity [15].

The phytotoxicity $\mathrm{ZnSO}_{4}$ indicated by decrease in growth and development and metabolism an induction of oxidative damage in various plant species. $\mathrm{ZnSO}_{4}$ toxicity in plants limited the growth of both root and shoot. Despite being an essential micronutrient for normal growth and development Zinc becomes phytotoxic and inhibit plant growth when in higher concentration. $\mathrm{ZnSO}_{4}$ may cause cytological disorder in plants, though much higher concentration are needed for affecting both patterns [16].

A number reports were given by different workers for studies of the effect on $\mathrm{ZnSO}_{4}$ on seedling growth of various plants gave a report on a drastic reduction of germination rice seedling. Their studies gave a clear picture roots are more responsive to metal compare to which support our present that on seedling growth.

We obtained almost similar results when we compare the effect of $\mathrm{ZnSO}_{4}$ growth of Oryza sativa L. seedlings with available literature. The inhibitory effect achieved in the present study may be due to higher dose than dose required by plant for its growth.

Under high $\mathrm{ZnSO}_{4}$ the chloroplast swells and grana being destroy in Oryza Sativa L. seedling. General symptoms of zinc toxicity are turgor loss, chlorosis and necrosis of leaves [17]. The excess $\mathrm{ZnSO}_{4}$ treatment bought about a marked depression in photosynthetic pigment like chl- $a$ and chl- $b$ in plants. It might be due to excess supply of $\mathrm{ZnSO}_{4}$ in interference with synthesis of chlorophyll.

In this above view chl- $a$, chl- $b$ and total chlorophyll content in exposed leaves slightly declined with increase in concentration of $\mathrm{ZnSO}_{4}$ which was measured in shoot of 10 day seedling. The findings also indicate that at higher concentration of metals cause leaves chlorosis and necrosis.

\section{Conclusion}

The present investigation of experimental induction of $\mathrm{Zn}$ stress to rice seedlings, showed decrease in seed germination, chl- $a$, chl- $b$ and total chlorophyll content and also decreases root and shoot growth of plants. It has also been observed that, the increase in $\mathrm{Zn}$ concentration has decreased the observed parameters significantly.

\section{Acknowledgements}

The authors are thankful to the Vice Chancellor, Khallikote University and Principal, Khallikote Autonomous College, Berhampur, Odisha for encouragement of research activity and providing necessary laboratory facilities.

\section{References}

[1] S.M. Impa, M.J. Morete, A.M. Ismail, R. Schulin, S.E. Johnson-Beebout, Zn uptake translocation and grain $\mathrm{Zn}$ loading in rice (Oryza sativa L.) genotypes selected for Zn-deficiency tolerance and high grain Zn, J. Exp. Bot. 64 (2013) 2739-2751.

[2] S. Krishnan, P. Dayanandan, Structural and histochemical studies on grainfilling in the caryopsis of rice (Oryza sativa L), J. Biosci. 28 (2003) 455-469.

[3] W. Jiang, P.C. Struik, H. Van Keulen, M. Zhao, L.N. Jin, T.J. Stomph, Does increased zinc uptake enhance grain zinc mass concentration in rice?, Ann. Appl. Biol. 153 (2008) 135-147.

[4] G. Hacisalihoglu, L.V. Kochian, How do some plants tolerate low levels of soil zinc? Mechanisms of zinc efficiency in crop plants, New Phytol. 159 (2003) 341350.

[5] C.Y. Wu, L.L. Lu, X.E. Yang, Y. Geng, Y.Y. Wei, et al., Uptake translocation and remobilization Zinc absorbed at different growth stages by rice genotypes of different Zn densities, J. Agric. Food Chem. 58 (2010) 6767-6773.

[6] R.A. Sperotto, F.K. Ricachenevsky, V. Waldow, A.L.H. Müller, V.L. Dressler, J.P. Fett, Rice grain Fe, Mn and $\mathrm{Zn}$ accumulation: How important are flag leaves and seed number?, Plant Soil Environ. 59 (2013) 262-266.

[7] H.J. Yin, X.P. Gao, T. Stomph, L. Li, F. Zhang, C.Q. Zou, Zinc concentration in rice (Oryza sativa L.) grains and allocation in plants as affected by different zinc fertilization strategies, Commun. Soil Sci. Plant Anal. 47 (2016) 761-768.

[8] T.J. Stomph, W. Jiang, P.E. Van Der Putten, P.C. Struik, Zinc allocation and reallocation in rice, Front Plant Sci. 5(8) (2014) 1-12.

[9] X.L. Ren, Q.L. Liu, D.X. Wu, Q.Y. Shu, Variations in concentration and distribution of health-related elements affected by environmental and genotypic differences in rice grains, Rice Sci. 13 (2006) 170-178.

[10] S.L. Jiang, J.G. Wu, Y. Feng, X.E. Yang, C.H. Shi, Correlation analysis of mineral element contents and quality traits in milled rice (Oryza sativa L), J. Agri. Food Chem. 55 (2007) 9608-9613.

[11] M. Wissuwa, A.M. Ismail, S. Yanagihara, Effects of zinc deficiency on rice growth and genetic factors contributing to tolerance, Plant Physiol. 142 (2006) 731741.

[12] R.L. Mabesa, S.M. Impa, D. Grewal, S.E. Johnson-Beebout, Contrasting grain-Zn response of biofortification rice (Oryza sativa L) breeding lines to foliar $\mathrm{Zn}$ application, Field Crop Res. 149 (2013) 223-233.

[13] S.M. Impa, A.S. Gramlich, S. Tandy, R. Schulin, E. Frossard, S.E. Johnson-Beebout Internal $\mathrm{Zn}$ allocation influences $\mathrm{Zn}$ deficiency tolerance and grain $\mathrm{Zn}$ loading in rice (Oryza sativa L), Front Plant Sci. 4(534) (2013) 1-10.

[14] D.I. Arnon, Copper enzymes in isolated chloroplast polyphenol oxidase in Beta vulgaris, Plant Physiol. 24 (1949) 1-15.

[15] W. Bergmann, Nutritional disorders of plants, W. Bergmann (Ed.), Nutritional disorders of plants, Gustav Fischer Verlag, COUNTRY, 1992.

[16] A.M.B. Pahlsson, Toxicity of heavy metals $(\mathrm{Zn}, \mathrm{Cu}, \mathrm{Cd}, \mathrm{Pb})$ to vascular plants: $\mathrm{A}$ literature review, water, Air Soil Pollut. 47 (1989) 287-319.

[17] S. Umar, Moinuddin, M. Iqbal, G.M. Vidyasagar, D. Kotresha, et al., Role of endosulfan in mediating stress responses in Sorghum bicolor (L.) Moench, J. Environ. Biol. 30(2) (2009) 217- 220. 